\title{
Health technology assessment in the United States
}

\author{
Bryan Luce, Rebecca Singer Cohen \\ United BioSource Corporation
}

Objectives: To describe and explore the reasons for the current health technology assessment (HTA) landscape in the United States.

Methods: Relying on multiple historical literature and other documents as well as drawing on personal experiences and observations, we describe, evaluate, and explain the evolving and dynamic HTA-related evidence landscape.

Results: The present HTA-related landscape is a product of a dynamic, somewhat turbulent path in the United States. Many early aggressive federal efforts beginning in the 1970 s were rejected in the 1980 s only to be revived by the mid-1990s and continue to strengthen today, likely due to diffusing private sector political opposition from de-linking HTA from policy decisions (e.g., coverage, clinical guidelines) and omitting economic evaluation. Meanwhile, private sector HTA efforts have remained active during the entire period.

Conclusions: The current HTA-related landscape is at least as dynamic as it has been at any point in its turbulent 30-year history and is likely to continue as health reform in the US is debated once again.

Keywords: USA, HTA, History, Health policy

Health technology assessment (HTA) is again alive and well in the United States, although, as we shall see, it has experienced a rather turbulent past and has changed somewhat to bend with political winds, at least at the national-federal level. However, today, as has been written of late, being "evidencebased" is de rigueur, and it is becoming clear that there is a growing policy and political interest and much rhetoric about improving the evidence base for informed healthcare decision making (23).

Most recently, discussions in the United States have included-possibly even turned to-establishing a reliable comparative effectiveness base of evidence, a term that may or may not include classic HTA activities. By 2009, policy discussions, position papers, symposia, sessions at scientific and health policy meetings, advocacy organizations, roundtables, legislative bills, hearings, testimonies, opinion pieces, and blogs seemingly were springing up weekly on the subject of producing better healthcare evidence.

This article attempts to paint the evolving present evidence landscape through a historical perspective by identifying several key players or stakeholders and their positions, discussing the major themes being addressed, and describing the underlying issues to be resolved, some of which are presently being considered.
To provide context to the policy issues being debated today, we begin with the historical context. A major reason to include this review is our déjà-vu observation, together with the realization that U.S. policy on contentious issues commonly is developed incrementally and often is tried, scaled back, and sometimes failed, only to resurface (sometimes) multiple times before it is finally adopted. In the United States, this pattern appears to be unfolding within the healthcare evidence debate today. Before we begin the historical journey, it will be useful to note that, although terminology has changed over the years, the underlying concepts remain quite similar. Unfortunately, there has been and continues to be some confusion in meaning. In fact, even the objectives of various key opinion and policy leaders sound convoluted, in part due to poorly specified terminology, such as interchangeably using the concepts of HTA, "evidence-based medicine" (EBM), and-more recently- "comparative effectiveness research" (CER). In Figure 1, we reproduce how one group of authors chose to depict the inter-relationships between HTA, EBM, and CER.

Although we think this depiction is useful, we are under no illusion that all stakeholders use these related terms exactly as depicted in Figure 1. A case in point is the positioning of HTA under the question "is it worth it?" Clearly, not all 


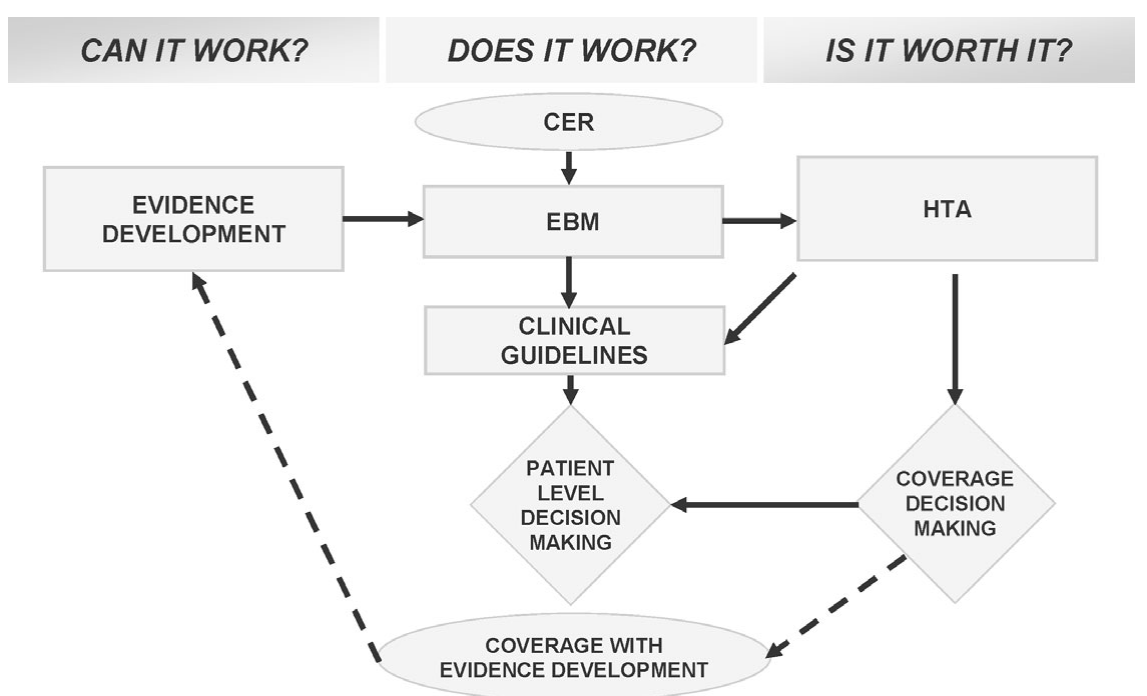

Figure 1. Relationships between commonly used terminologies. CER, comparative effectiveness research; EBM, evidencebased medicine; HTA, health technology assessment. Source: (9).

HTA activities specifically address the economic dimension subsumed within this definitional positioning. Furthermore, for the remainder of this chapter, we will commonly refer to "HTA-related" or "HTA-like" activities-as opposed to HTA or EBM or CER - due to the lack of clarity in the way these terms are used or intended.

\section{BACKGROUND}

\section{Initial Federal Efforts to Establish Health Technology Assessment in the United States}

The EBM and later the CER policy discussions, so front and center in 2008-09 in the United States, are actually the latest in a long line of related proposals, policies, and initiatives begun in the United States at least as long ago as the mid1970s. It was then that Congress established its own Office of Technology Assessment (OTA), with its prominent health program as described in the study by Banta and Jonsson in this issue (4). This congressional "think tank" was soon followed by the congressionally established National Center for Health Care Technology (NCHCT), which reported to the U.S. Public Health Service. Together, they were seminal in defining and promoting the concept initially known as "medical technology assessment," later to be re-designated "health technology assessment." Congress created these HTA structures and policies because it believed that healthcare technology was widely diffusing throughout the healthcare system before it was properly evaluated for its effectiveness, cost-effectiveness, and-to a lesser extent-safety.

The next decade (1980s) began by building on the HTA movement. The National Academy of Sciences' prestigious Institute of Medicine created a Council on Health Care Technology (14) that was, in part, perhaps the first attempt in the
United States to spawn a private-public technology assessment partnership. Soon thereafter, the U.S. private health insurance industry (specifically Prudential) proposed and lobbied for a "private-public" consortium to fund a broad national HTA initiative. Later in the decade, the Health Care Financing Administration (now called the Centers for Medicare and Medicaid Services, or CMS) proposed that Medicare adopt cost-effectiveness analysis as one factor for coverage decisions (19).

At least one other HTA-related movement (continuing to this day) also played a pivotal role during the latter part of this and later periods. This was Dr. John Wennberg's successful health services research campaign that established evidence of disturbingly high medical and surgical practice variation by geographic area (26; see also 10$)$. These geographic disparities could not be supported by evidence showing that the variation made a difference in outcomes; whereas, there was strong evidence that it made a huge difference in healthcare costs. Wennberg's research-indeed, his enormously effective public education campaign-led to the Medicare "effectiveness" initiative and to Congress establishing the Agency for Health Care Policy and Research (AHCPR) in 1989 (5). Within this new agency, the Center for Medical Effectiveness Research had primary responsibility for administering grant and contract research under its new Medical Treatment Effectiveness Program. This program was charged to improve the effectiveness and appropriateness of medical practice by developing and disseminating scientific information regarding the effects of presently used healthcare services and procedures on patients' survival, health status, functional capacity, and quality of life. To fulfill this charge, the government funded many multidisciplinary, academically based "Patient Outcomes Research Teams," or PORTs, as they were known. Each team had a therapeutic focus (e.g., back pain, myocardial infarction, cataract surgery), and the 
objective of each 5-year, $\$ 5$ million budget was to determine "what worked"- that is, what is spoken of today as "comparative effectiveness" evidence. In fiscal year 1990, \$38 million were allocated to this national evidence development effort. PORTs accomplished their work mainly by reviewing effectiveness evidence from the literature, with a generous dose of data analysis from Medicare claims. No de novo clinical effectiveness (e.g., trial) research was included or, to our knowledge, even contemplated.

Another notable policy was the Congressional mandate for AHCPR to develop and disseminate clinical guidelines across therapeutic categories based on systematic evidence reviews, such as those undertaken by the PORTs. In some cases, guidelines were directly linked to the PORT evidence synthesis activities.

In addition, by at least the early 1980s, the agency established the Office of Health Technology Assessment (OHTA) - remnants of which continue to this day-which conducted formal, full assessments, often at the specific request of Medicare (5).

During this time, other federal agencies also had active HTA-related programs, perhaps most prominently that of the Veterans Health Administration (VHA).

The VHA has had a long-standing commitment to HTA. The function was traditionally housed in the Health Services Research and Development Service (HSR\&D), but in 2000 it moved internally to the Office of Patient Care Services (PCS), where it resides to this day (25; personal communications with Elizabeth Adams, December 2008).

Presently, there is no single focal point within the VHA for the comprehensive collection and analysis of highquality evidence to advise healthcare decision makers. Several groups provide different forms of HTA within the VHA, such as the PCS Technology Assessment Program (TAP), the Health Analysis and Information Group, the Medical Advisory Panel of the Pharmacy Benefits Management Strategic Health Group, the Office of Quality and Planning, and the Office of Research and Development. All provide valuable information in their own right, but for different purposes and with limitations.

Most recently, in 2005 PCS established the VHA Technology Assessment Advisory Group (TAAG). Its mission is to provide scientifically rigorous, evidence-based policy recommendations to the VHA National Leadership Board (NLB)'s Health Systems and Finance Committees that maximize patient care quality and outcomes through technologies used in veterans' health care. The TAAG is a multidisciplinary group of veterans' affairs (VA) experts with diverse clinical, health systems, and health services research backgrounds that provide varied and objective points of view.

The TAAG is responsible for establishing a process for selecting and prioritizing topics for evaluation, for quality assurance of the overall HTA process, and for preparing policy recommendations to the NLB regarding technologies used in the VHA. The TAAG is also tasked with convening appropriate ad hoc panels of practitioners and experts in disease management (but not in the relevant technologies, per se) to inform the appropriate clinical context for each issue. The TAP supports the TAAG by providing scoping and comprehensive searches to determine the adequacy of the evidence base on each topic, as well as independent, qualitative systematic review guided by de facto experts for clinical guidance and peer review. Today, the VHA integrates HTA in institutional cost/benefit and acquisition decisions on healthcare technology across the system.

Another related issue is that, for some time now, the VHA has invested in a state-of-the-art health information system that incorporates an electronic medical record system, which assists researchers in evaluating medical care (including the use of medical technologies).

\section{Many Federal HTA Efforts Fail}

By the early 1990s, most of the above federal and "privatepublic" HTA and evidence-related efforts had failed. The NCHCT was defunded in 1981 after only several years in operation; the IOM's Health Care Technology Council, established in 1977, was out of business by 1981; the health insurance industry-inspired private-public HTA partnership never got off the ground; OTA was defunded in 1995; AHCPR was forced out of the clinical guideline business and came close to being entirely defunded by Congress; and, notwithstanding multiple attempts, Medicare has to this day not been able to adopt cost-effectiveness as a coverage criterion (17).

Why did these efforts fail? They failed due to four politically charged factors. First, HTA was perceived as a threat to investing in innovative medical technologies. This was personified by the extreme concern expressed by medical product manufacturers, supported by organized medicine, over NCHCT's "hit list" (as it was viewed by opponents) of "emerging" medical innovations to be considered for evaluation before they diffused into the marketplace. Second, HTA was perceived to threaten organized medicine's medical autonomy. Third, HTA was perceived to threaten access to the latest innovations by patient advocacy groups. Fourth, to the extent that economic evaluation was included, HTA was seen by these stakeholders as a way to ration health care to contain cost. Collectively, these four concerns spawned fierce and effective political opposition largely focused on Congressional lawmakers, resulting in the above-noted HTA policy-related reversals. Meanwhile, however, the dynamic U.S. healthcare private sector was experiencing no such backlash.

\section{A Sampling of HTA Organizations and Efforts in the Private Sector}

During the first two tumultuous decades at the federal level, there were multiple and continuous private-sector HTArelated activities among health insurers, medical societies, and the hospital sector-many of which were, and continue 
to be, successful. Here we provide a brief description of several seminal, long-standing private-sector HTA efforts across the United States. The reader should note that the organizations selected below are among the more prominent and long-standing examples, rather than an inclusive list of the full scope of such organizations in the United States. The examples listed here were selected to encompass the characteristic nature of the HTA-related activities across the country. Most of these initiatives are generally highly regarded and noncontroversial, and have kept the HTA movement and culture within the United States alive and well, if not actually thriving during the turbulent years at the federal level.

The BlueCross BlueShield Association (BCBSA) initiated its HTA efforts in 1977 with the Medical Necessity Program (MNP) (22). Early efforts focused on identifying obsolete procedures, and findings were made publicly available. In 1985, BCBSA added a coverage-focused HTA process when it established the Technology Evaluation Center (TEC), which continues to be active today. Its reports are considered private and are made available to its member plans and to others on a subscription basis. TEC's stated mission is "to provide health care decision makers with timely, rigorous, and credible assessments that synthesize the available evidence on the diagnosis, treatment, management, and prevention of disease." TEC was designated as one of the first Evidence-based Practice Centers of the Agency for Healthcare Research and Quality (AHRQ) in 1997 and has received subsequent 5-year re-appointments to this day (6).

In 1981, the American College of Physicians (ACP) established the Clinical Efficacy Assessment Project (CEAP), which initially evolved from the BCBSA's Medical Necessity Program (22). The goals were to assemble and review the clinical literature on a specified topic; to identify the best scientific papers; and to analyze, reformulate, and present such information so that practitioners can readily determine the usefulness of diagnostic tests, procedures, or treatments.

The initial charge from CEAP was to evaluate medical advances. Early ACP guidelines addressed diagnostic tests and technologies. These guidelines focused on topics developed through surveys of the ACP membership and were chosen based on the interest of the internal medicine community. Today, ACP generates clinical guidelines based largely on publicly available comprehensive evidence reports developed by AHRQ-funded Evidence-based Practice Centers (3).

The American Medical Association began its Diagnostic and Therapeutic Technology Assessment (DATTA) program in 1982 (22). Initially, technology reports were generated by polling the opinions of clinical experts but were later supplemented by more systematic literature review when that came into vogue. By the mid-1990s, DATTA began winding down, and it ceased functioning by the end of 1998 (personal communications with Karl Matuszewski, December 2008).

The American Hospital Association (AHA) also initiated its Hospital Technology Series program in 1982. The purpose of this HTA program was to help hospital managers keep abreast of technology innovations, with an eye toward capital budgeting, staffing, training, maintenance, and the provision of clinical services. This effort evolved into publications focused on major hospital service departments (e.g., diagnostic imaging, surgery) and especially on costly technologies such as positron emission tomography (PET). The HTA program wound down by the mid-1990s, and today AHA maintains a much more scaled-down program (13).

The ECRI Institute began operations in 1955 as the Emergency Care Research Institute. By 1971, it had refocused its activities to HTA, establishing the Health Devices Program. Today, it has broadened its activities beyond traditional HTA to include technology planning, procurement and management, patient safety, quality and risk management, healthcare policy and research, and health care environmental management. In 1997, it was designated an AHRQ Evidence-based Practice Center, which also continues to this day (11).

\section{HTA and the Pharmaceutical Private Sector: The Rise of Pharmacoeconomics}

Of interest, while the U.S. medical products industry, including the pharmaceutical sector, actively and effectively lobbied against public-sector HTA, by at least the mid-1980s it embarked on creating its own private-sector HTA-like movement. The rationale was to market new pharmaceuticals on total value, which initially typically meant conducting costeffectiveness analyses. One by one, each major firm established its own mini-HTA-like group, initially termed "health economics" departments and later named "health economics and outcomes research" (HEOR) departments, especially as health-related quality of life (now termed "patient-reported outcomes," or PROs) became a standard health outcomes measure. Furthermore, to serve this new business opportunity, a veritable industry of contract private-sector HTA-like research firms emerged, some within not-for-profit organizations (e.g., at RTI and Battelle) but mostly in for-profit firms (e.g., MEDTAP International, now UBC; Policy Analysis Inc; Health Technology Associates) and related practices within large vendor companies (e.g., Quintiles, MEDSTAT, IMS, Covance).

Thus was born the quasi-HTA-like discipline that came to be known as "pharmacoeconomics," and with it a society (International Society of Pharmacoeconomics and Outcomes Research [15]; www.ispor.org) with its own journal, Value in Health (http://www.ispor.org/valueinhealth_index.asp).

Within the next decade, the U.S. private-sector pharmacy departments of health insurers and health providers began structuring their own HTA-like processes. For instance, in 2000, the Academy of Managed Care Pharmacy (AMCP) published version 1.0 of its Format for Formulary Submission, which is an HTA-like methods guide for managed care pharmacy departments to assess the clinical, humanistic, and 
economic evidence of new and existing pharmaceutical products (1). Today, many individual health insurers (e.g., Premera) and health care plans have adopted the AMCP Format process; others (e.g., Wellpoint, Kaiser) have developed their own, albeit similar, HTA processes and internal organizational structures.

\section{Medicaid, Consumers Union, and the Drug Effectiveness Review Project}

In 2003, the Oregon Health and Sciences University established the Drug Effectiveness Review Project (DERP) to develop comparative effectiveness reports of drugs within class, relying mostly on existing randomized controlled trial (RCT) clinical literature (20). DERP's clients consist mainly of up to fourteen state Medicaid agencies that use the evidence reports to inform their drug formulary decisions, in some cases to develop preferred drug lists. In many ways, DERP's process is more highly structured than other HTA-like efforts noted above, especially with respect to the formal analysis of clinical data and the inclusion/exclusion rules of evidence it considers as legitimate. In addition, these drug-class assessment reports are used by two sentinel U.S. consumer organizations-Consumers Union through its Best Buy Drugs feature (8) and the AARP, formerly called the American Association of Retired Personsfor interpretation and dissemination to their consumer constituencies (12).

\section{Institute of Medicine's Roundtable on Evidence-based Medicine}

We close this discussion of HTA-like activities with a brief introduction to the IOM's Roundtable on Evidence-Based Medicine (16). The roundtable is a recently constituted, broadly focused, senior stakeholder-led, national effort designed to help transform the way evidence on clinical effectiveness is generated and used to improve health and health care. The roundtable's vision calls for a healthcare system that draws on the best evidence to provide the care most appropriate to each patient, emphasizes prevention and health promotion, delivers the most value, adds to learning throughout the delivery of care, and leads to improvements in the nation's health. Its stated goal is "by the year 2020, 90 percent of clinical decisions will be supported by accurate, timely, and up-to-date clinical information, and will reflect the best available evidence."

All in all, these numerous private sector HTA efforts have succeeded because they appear to be viewed by the various sponsoring organizations as useful for informing clinical decision making, purchasing expensive medical equipment, making insurance coverage decisions and formulary placement of drugs, and - in some cases - as an aid to cost containment.

\section{Renewed Federal Interest in HTA-related Policies}

The Medicare Modernization Act and the Agency for Healthcare Research and Quality. In 2003, Congress enacted the Medicare Modernization Act (Pub. L. 108-173) which, among other things, created the Effective Health Care program within the newly named Agency for Healthcare Research and Quality (2). This program oversees a series of mainly academically based HTA-related research centers. The fourteen Evidence-based Practice Centers (EPCs) conduct broad systematic literature reviews to determine the state and quality of evidence for specific questions. AHRQ's DEcIDE (Developing Evidence to Inform Decisions about Effectiveness) Network consists of thirteen research centers that develop new evidence using administrative and electronic medical record databases. The agency also administers the Centers for Education and Research on Therapeutics (CERT) program, a national initiative cosponsored by the Food and Drug Administration to conduct research and provide education that advances the optimal use of drugs, medical devices, and biological products. Thus, in 2008, the federal government already is funding forty-one HTArelated research centers that are charged with interlockingperhaps somewhat overlapping - evidence-related responsibilities, including (within the CERT program) several publicprivate partnerships.

\section{Medicare Coverage Policy}

Also notable during this time period, the Centers for Medicare and Medicaid Services established more formal HTAlike policies to inform coverage decisions for Medicare, primarily by establishing the Medicare Evidence Development and Coverage Advisory Committee (MedCAC). The Med$\mathrm{CAC}$ is made up of a large number of academics, clinical specialists, and various other private-sector advisors, and is charged with reviewing scientific evidence and advising Medicare on specific national coverage issues. In addition, for special cases, and as it has for many years, Medicare will request AHRQ to conduct a formal HTA (7). Most CMS evidence-related coverage determination efforts have and still do rely on synthesizing existing clinical and, often, health services research literature by means of formal or informal systematic reviews. These research methods have been improving over at least the past decade. However, of recent note, CMS is testing a new, more dynamic HTA-like policy called "coverage with evidence development."

\section{Coverage with Evidence Development Policy}

In July 2006, in a potentially major shift in HTA scope, CMS issued a guidance document titled "National Coverage Determinations with Data Collection as a Condition of Coverage: Coverage with Evidence Development (CED)." This document describes how Medicare is attempting to 
integrate evidence development policy into its national coverage decisions (Social Security Act $§ 1862(a)(1))$. In effect, CMS is integrating HTA synthesis of existing evidence ("traditional" HTA-like activities) with the de novo-perhaps experimental-new evidence of clinical effectiveness. Two CED categories emerged: national coverage determinations, labeled as "Coverage with Appropriateness Determination (CAD)"; and "Coverage with Study Participation (CSP)." Both are considered to be a form of what is being termed "conditional coverage," and both require prospective evidence collection. For instance, a national coverage determination that requires a CAD indicates that CMS believes that sufficient evidence has been provided to recommend coverage - but only for patients and services described in the submitted data - and, furthermore, that evidence must continue to be collected to ensure proper ("appropriate") treatment. Thus, CAD is designed to ensure appropriateness of treatment relative to the use of a technology or service.

CSP is different and is closer to a research study concept. It allows coverage for a promising treatment or service with the condition that information be collected within a research setting on its progress to inform future coverage. Under this policy, coverage has been extended for beneficiaries who participate in a prescribed clinical study. Examples include a registry of implantable cardiac defibrillators, a registry of PET for Alzheimer's disease treatments, and an RCT for offlabel colorectal cancer treatments. Thus, in CED, Medicare has integrated HTA, new evidence development, and, presumably, evidence-based decision making into its coverage determination policies.

Medicare's CED policy is consistent with a new dimension in HTA-like evidence policy, spoken of in the United States as "comparative effectiveness research" (CER). In some circles, CER is interpreted to mean pragmatic clinical trials (PCTs) to highlight the aim of achieving evidence of real-world effectiveness (24).

\section{Federal Commitment for Comparative Effectiveness Research}

In November 2006, Dr. Gail Wilensky authored an article published in the prominent and influential policy journal Health Affairs that spawned a wave of discussion surrounding major new investment for a new national center or institute for comparative effectiveness research (27).

Wilensky envisioned that this entity would undertake independent comparative assessments of both alternative therapies and procedures, and would require several billions of dollars to conduct real-world (what some call "pragmatic") comparative trials. Her proposal was rapidly followed by roughly similar proposals and advocacy positions by numerous prominent public and private organizations and opinion leaders, including the Institute of Medicine the American Academy of Physicians, BlueCross BlueShield Association and other payer associations, employer groups, and, of par- ticular policy importance, the Congressional Budget Office. By 2007, Congressional committees in both the House of Representatives and the Senate were generating legislation to create such an entity.

With the change in administrations following the November 2008 election of Obama as president and with a new Congress, the massive economic stimulus bill (H.R. 1, the American Recovery and Reinvestment Act of 2009) was passed. Embedded within this new law was $\$ 1.1$ billion dollars for investment in comparative effectiveness research allocated as follows: $\$ 300$ million for AHRQ, $\$ 400$ million for the National Institutes of Health (presumably to focus on comparative trials), and an additional $\$ 400$ million for the Secretary of HHS. In addition, the Secretary was directed to establish a "Federal Coordinating Council for Comparative Effectiveness Research" comprised of fifteen federal government officials from a variety of relevant agencies, half of whom must be physicians.

\section{DISCUSSION}

The history of the HTA landscape in the United States undoubtedly reflects the country's historical roots of distrust of central government authority and a reliance on free market capitalism even in health care. It has led to an inability to adopt universal health insurance or to centrally plan and regulate healthcare services as is typically seen in other Western countries.

Since the early 1990s, the United States has witnessed a renewed commitment to HTA and other evidence-related activities. There appear to be several dynamics that have converged over time that have served to stimulate this renewed federal interest in improving evidence for healthcare decision making, including specific HTA-related policy development. Most important are the concurrent issues of (i) continued and inexorable healthcare cost increases in federal spending and (ii) increasing scientific and political awareness that the evidence base for informed decision making is not improving, and may in fact be worsening. For instance, throughout 2008, former Director of the Congressional Budget Office (CBO), Dr. Peter Orszag, was fond of displaying Figures 2 and 3 in his many talks on the merits of investing in comparative effectiveness. The first depicts the excessive expected growth of federal spending for health care; the second depicts the lack of association between quality and cost of health care.

Thus the cost, quality, and dearth of evidence of effectiveness and value concerns that led to the earlier federal HTA policies - many of which ultimately failed - were not only present by the early 1990s but had grown. However, what made the difference from a political opposition standpoint was the manner and tenor in which the renewed federal HTArelated policies evolved. For instance, cost and cost evaluation (e.g., cost-effectiveness analysis) was, and continues to be, de-emphasized, while clinical effectiveness and safety have been the focus. (Whether de-emphasizing economic 


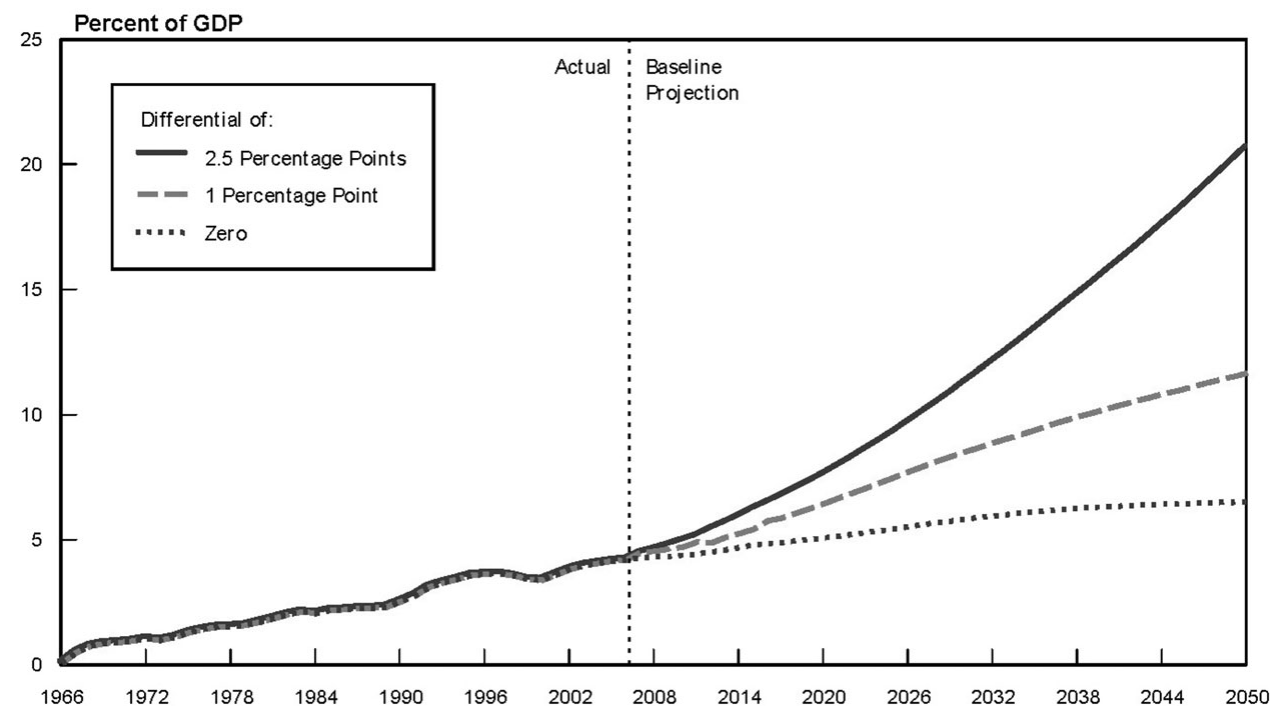

Figure 2. Federal spending for Medicare and Medicaid as a percentage of gross domestic product under different assumptions about excess cost growth. Note: Excess cost growth refers to the number of percentage points by which the growth of annual healthcare spending per beneficiary is assumed to exceed the growth of nominal gross domestic product per capita. GDP, gross domestic product. Source: (21).

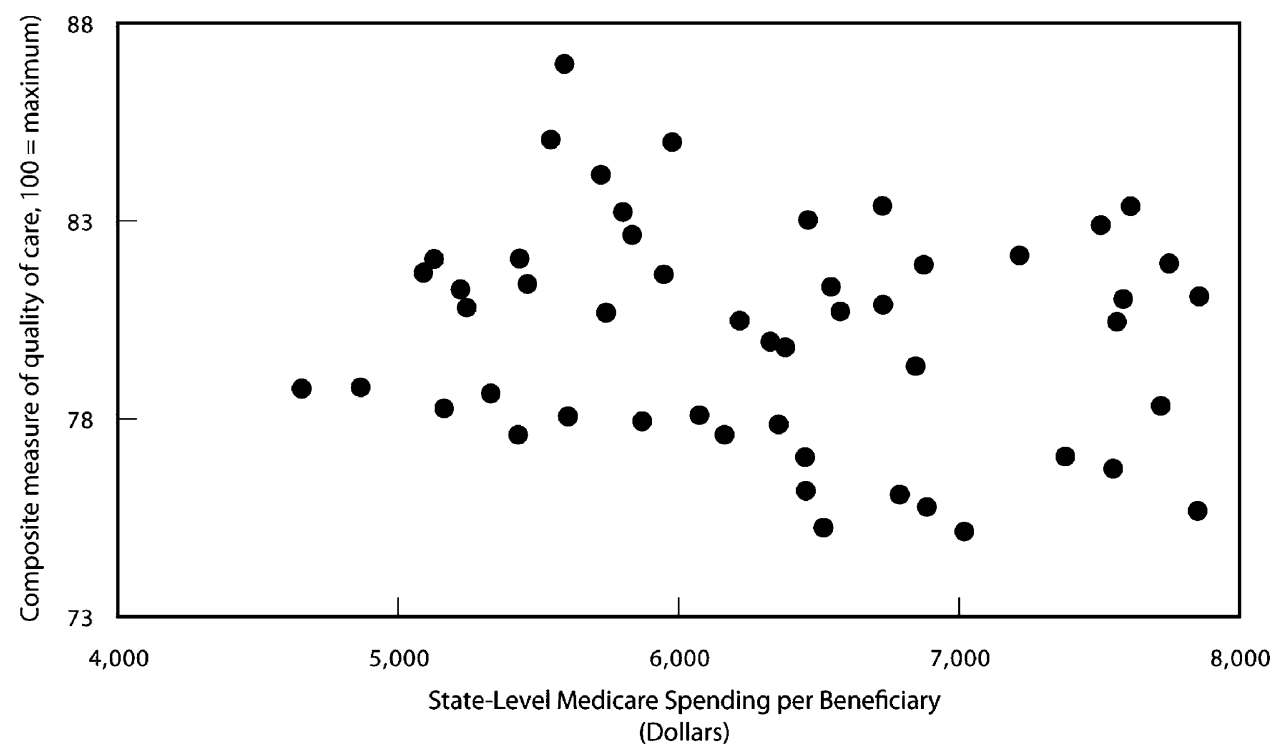

Figure 3. Relationship between quality of care and Medicare spending, by state, 2004. Geographic variation in health care spending. February 2008. Based on data from the Centers for Medicare and Medicaid Services and the Agency for Healthcare Research and Quality. Note: The composite measure of quality reflects the provision of recommended care to patients hospitalized with acute myocardial infarction, heart failure, or pneumonia. Source: Statement by Peter R. Orzag, Director, Congressional Budget Office. "Opportunities to Increase Efficiency in Health Care," presented at Health Reform Summit of the Committee on Finance, United States Senate. June 16, 2008.

evaluation is sustainable in even the medium term given current cost projections is, of course, highly questionable).

In addition, federally sponsored evidence-development activities have been carefully crafted to be at arms' length from policy development, especially coverage policy decision making. For instance, the 2003 Medicare Modernization Act (MMA), which funded AHRQ's EPCs, specifically prohibits the use of these HTA-like reports to deny Medicare coverage! Also notable is the fact that the massive 2009 comparative effectiveness research federal funding is silent about linking the newly expected developed evidence with policy decision making. However, because the funding is awarded to AHRQ to perform its functions under MMA Section 1013 (as specified in the legislation), it can be presumed that these 
same restrictions apply. One can question the sustainability of this "de (or non)-linking" policy as well. The political sensitivity can also be seen in the fact that Medicare justifies its coverage with evidence development policy expressly to enhance adoption and market access to innovative medical technologies, drugs, and biologics, rather than to control or slow diffusion of them. Taken together, the new, more politically sensitive way in which federal HTA-like policies have been both legislated and implemented has somewhat defused political opposition to them from the medical products industry, organized medicine, and patient advocacy groups. Similarly, federal advisory groups such as the Medicare Payment Advisory Commission (MedPAC) have emphasized the need for an increased investment in comparative effectiveness research, going so far as to endorse the creation of a separate entity to coordinate such research (18).

To sum up, the United States has experienced dynamic, yet uncertain and at times disconcertingly erratic, HTArelated policy developments at the federal level over the past 30-plus years. However, since perhaps the mid-1990s, the current HTA-related landscape is at least as dynamic as it has been at any point in its turbulent history-but mostly in a positive, building sort of way. Multiple legislative, administrative, and research agendas are being formed due to the acknowledged importance of formally developing and incorporating evidence into ongoing best clinical practices, coverage policy, and other healthcare decision making. The result is a landscape dominated by several activities, proposals, and position statements across the private- and public-sector spectrum delineating what a federal HTA-related agenda should be. Of late, this national agenda is more often referred to in terms of EBM or comparative effectiveness than it is to HTA. Notwithstanding all this activity, the proverbial "elephant in the room" is, of course, cost and value, which virtually all observers realize will ultimately have to be dealt with explicitly within both the public- and private-sector spheres. All in all, we think it can be stated that the spirit and ultimate aim of the HTA concept appear to be alive and gaining momentum in the United States, particularly in light of the recent $\$ 1.1$ billion federal dollars for comparative effectiveness research efforts.

\section{CONTACT INFORMATION}

Bryan R. Luce, PhD (bryan.luce@unitedbiosource.com), United BioSource Corporation, Senior Vice President, Science Policy, Rebecca Singer Cohen, MPP (rebecca. singercohen@unitedbiosource.com), Science Policy Analyst, United BioSource Corporation, 7101 Wisconsin Avenue, Suite 600, Bethesda, Maryland 20814

\section{REFERENCES}

1. Academy of Managed Care Pharmacy (AMCP). The AMCP format for formulary submissions, version 2.0. http://www. amcp.org/data/nav_content/formatv20.pdf (accessed August 29, 2006).
2. Agency for Healthcare Research and Quality. Effective health care. Homepage. http://effectivehealthcare.ahrq.gov/ (accessed August 29, 2006).

3. American College of Physicians. ACP clinical practice guidelines. http://www.acponline.org/clinical_information/ guidelines/ (accessed August 29, 2006).

4. Banta D \& Jonsson E. History of HTA: Introduction. Int J Health Care Technol. 2009; 25(suppl. 1) 1-6.

5. Banta HD, Luce BR. Health care technology and its assessment. Oxford: Oxford University Press; 1993.

6. BlueCross BlueShield Association: Technology Evaluation Center (TEC). AHRQ evidence-based practice center. http://www.bcbs.com/blueresources/tec/evidence-basedpractice-center.html (accessed August 29, 2006).

7. Centers for Medicare and Medicaid Services. Medicare evidence development and coverage advisory committee. http:// www.cms.hhs.gov/FACA/02_MEDCAC.asp (accessed August 29, 2006).

8. Consumer Reports Health. Consumer Reports best buy drugs. http://www.consumerreports.org/health/best-buy-drugs/ index.htm (accessed August 29, 2006).

9. Drummond MF, Schwartz JS, Jönsson B, et al. Key principles for the improved conduct of the health technology assessments for resource allocation decisions. Int J Technol Assess Health Care. 2008;24:244-258.

10. Dartmouth atlas of health care. Available at: http://www. dartmouthatlas.org. Accessed: 29 August 2006.

11. ECRI Institute. Evidence-based practice center. https:// www.ecri.org/About/Pages/EvidenceBasedPracticeCenter.aspx (accessed August 29, 2006).

12. Gross DJ, Schondelmeyer SW, Purvis L. Rx watchdog report: Trends in prices of prescription drugs used by Medicare beneficiaries. http://www.aarp.org/research/health/drugs/ rx_watchdog.html (accessed August 29, 2006).

13. Health Tech. What's new at HealthTech. http://www. healthtechcenter.org/ (accessed August 29, 2006).

14. Institute of Medicine. Appendix A: About the Council on Health Care Technology and rosters of council and panels. In: Medical Technology Assessment Directory: A pilot reference to organizations, assessments, and information resources. Washington, DC: Institute of Medicine; 1988:631640.

15. International Society for Pharmacoeconomics and Outcomes Research. Homepage. http://www.ispor.org/ (accessed August 29, 2006).

16. The Learning Healthcare System. Workshop summary. Washington, DC: Institute of Medicine; 2006.

17. Levin-Epstein M. Deathwatch for AHCPR ends as funding mandate changes. Managed Care Magazine. September 1999.

18. Medicare Payment Advisory Committee (MedPAC). Report to the Congress: Promoting greater efficiency in Medicare. June 2007. http://www.medpac.gov/documents/jun07_ entirereport.pdf (accessed August 29, 2006).

19. Neumann PJ. Using cost-effective analysis to improve health care: Opportunities and barriers. Oxford: Oxford University Press; 2005.

20. Oregon Health and Science University. Drug Effectiveness Review Project (DERP). http://www.ohsu.edu/drugeffectiveness/ (accessed August 29, 2006) 
21. Orzag PR, Ellis P. The challenge of rising health care costs-A view from the Congressional Budget Office. $N$ Engl J Med. 2007; 357:1793-1795.

22. Rettig RA. Health care in transition: Technology assessment in the private sector. Los Angeles, CA: Rand; 1997.

23. Steinberg EP, Luce BR. Evidence based? Caveat emptor! Health Aff (Millwood). 2005;24:80-92.

24. Tunis SR, Stryer DB, Clancy CM. Practical clinical trials: Increasing the value of clinical research for decision making in clinical and health policy. JAMA. 2003;290:1624-1632.
25. United States Department of Veterans Affairs. Technology assessment: An effective resource for evidence-based managers. VA Technology Assessment Program VATAP. http://www.va.gov/VATAP/ (accessed August 29, 2006).

26. Wennberg JE. Dealing with medical practice variation: A proposal for action. Health Aff (Millwood). 1984;3:632.

27. Wilensky GR. Developing a center for comparative effectiveness information. Health Aff (Millwood). 2006;25:572585 . 